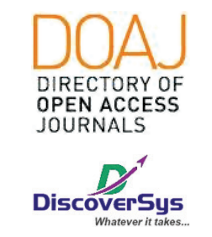

Published by DiscoverSys

\section{Mean platelet volume count as a risk factor for bloodstream infection in Pediatric Ward Sanglah General Hospital Denpasar, Bali-Indonesia}

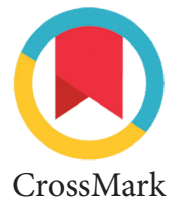

\author{
Ni Putu Wirantari, ${ }^{1 *}$ I Wayan Gustawan, ${ }^{1}$ Made Gede Dwilingga Utama, ${ }^{1}$ \\ Bagus Ngurah Putu Arhana, ${ }^{1}$ Ni Nengah Dwi Fatmawati, ${ }^{2}$ Ni Made Adi Tarini ${ }^{2}$
}

\title{
ABSTRACT
}

Background: Mean platelet volume (MPV) is a potentially interesting parameter in predicting bacteremia in patients admitted with suspected community-acquired infections. The incidence of bacteremia, defined as the presence of viable bacteria in the bloodstream, in patients who were being admitted to hospital. Multiple recent studies have confirmed that low-level bacteremia is more common than previously thought, occurring in 38\% to $68 \%$ of all pediatric patients with a positive blood culture. The mortality rate is $25 \%-30 \%$, increases to $50 \%$ when associated with severe sepsis. The objective of this study is to investigate whether MPV as a risk factor for bloodstream infection.

Methods: This was a hospital-based case-control study, review of the medical record from January 2016 until December 2018. We collect age, gender, MPV, platelet and blood culture. We analyze the association between MPV to bloodstream infection.
Result: Between January $1^{\text {st }} 2016$ and December $31^{\text {st }} 2018$, there were 86 patients with positive blood cultures and 89 negative blood cultures. In the case group, there were 48 (53.9\%) male and 41 (46.1\%) female subjects, while in the control group there were $63(73.3 \%)$ male and 23 (26.1\%) female subjects. The median age for case group was 14 months while the median age for control group was 23 months. From the ROC curve, the optimal cutoff value for MPV was determined as 5.59. The odd ratio determined the relationship between MPV to blood stream infection was 2,26 with $95 \% \mathrm{Cl} 1.13-4.52$. The adjusted odds ratio was $2.2495 \% \mathrm{Cl}$ (1.10-4.57). The majority diagnosis was pneumonia (46.1\%) in case group then early onset neonatal sepsis (28.1\%) and meningitis (7.9\%).

Conclusion: The MPV $\geq 5.59$ is a risk factor for developed bloodstream infection. This result can be used as a cutoff point to initially administered antibiotic to prevent the worse prognosis (sepsis, multiple organ failure, and death).

Keywords: mean platelet volume, bloodstream infection, risk factor.

Cite this Article: Wirantari, N.P., Gustawan, I.W., Utama, M.G.D., Arhana, B.N.P., Fatmawati, N.N.D., Tarini, N.M.A. 2020. Mean platelet volume count as a risk factor for bloodstream infection in Pediatric Ward Sanglah General Hospital Denpasar, Bali-Indonesia. Intisari Sains Medis 11(1): 55-59. DOI: 10.15562/ism.v11i1.553

'Departement of Child Health, Faculty of Medicine Udayana University/Sanglah Hospital Denpasar, Bali-Indonesia

${ }^{2}$ Departement of Clinical Microbiology, Faculty of Medicine Udayana University/Sanglah Hospital Denpasar, Bali-Indonesia

${ }^{*}$ Correspondece to: Ni Putu Wirantari, Departement of Child Health, Faculty of Medicine Udayana University/ Sanglah Hospital Denpasar, BaliIndonesia

ariwirantari@yahoo.co.id

Received: 2019-06-27 Accepted: 2020-01-03 Published: 2020-04-01

\section{INTRODUCTION}

Sepsis is a condition in which life-threatening organs dysfunction occurs due to immune dysregulation against infection. ${ }^{1}$ Sepsis has affected millions of people each year, and is associated with high morbidity, mortality and care costs, and is a major cause of infant and child mortality worldwide. The incidence of sepsis has increased in recent years, especially in developing countries. ${ }^{2}$ Based on epidemiological studies in seven states in the United States, the incidence of severe sepsis is 0.56 cases per 1000 population per year, with the highest incidence in the infant age group (5.16 cases per 1000 population) and decreasing in the 10 - 14 years old group ( 0.2 cases per 1000 population). The same study found more than 4383 deaths per year or $10.3 \%$ of total deaths in children caused by severe sepsis. ${ }^{3}$

Mean platelet volume (MPV) is a simple and accurate marker of size functional status of platelets. Several studies have shown that cytokines such as interleukin-3 (IL-3) or interleukin-6 (IL-6) in sepsis patients will affect megakaryocyte ploidy and can cause more reactive and larger platelet production. Therefore, platelet volume is an indirect marker of increased platelet reactivity in sepsis. ${ }^{4}$ Increased MPV indicates an increase in platelet production as well as young platelets with a larger size and more reactive to aggregate. ${ }^{5}$

Mean platelet volume is a potentially interesting parameter in predicting blood stream infection/ bacteremia in patients admitted with suspected community-acquired infections. The incidence of bacteremia, defined as the presence of viable bacteria in the bloodstream, in patients who were being admitted to hospital. Multiple recent studies have confirmed that low-level bacteremia is more common than previously thought, occurring in $38 \%$ to $68 \%$ of all pediatric patients with a positive blood culture. ${ }^{6}$ The mortality rate is $25 \%-30 \%$, increased to $50 \%$ when associated with severe 
sepsis. Patients with bloodstream infection (BSI) have worst outcomes rather than negative blood culture controls, and so early treatment improves the outcome. Bacterial infection has ability to make systemic inflammation, which is characterized by fever. Fever is common in patients presented to hospital, but blood culture-confirmed bacterial BSI had only small proven. ${ }^{7}$

MPV is easily calculated and immediately available from the complete blood count. Several studies have demonstrated that MPV increases in septic patients and it has been hypothesized that activated platelets are altered in terms of shapes and sizes. Larger platelets are functionally, metabolically, and enzymatically more active than smaller ones and produce chemokines and cytokines. ${ }^{8}$ In the literature many studies have discussed the changes in MPV values in septic patients specifically in adults and neonates. Catal et al. grouped the preterm infants in their study as control $(n=100)$ and sepsis $(n=91)$. They showed a significant increase in the MPV in the case of the sepsis group and reported that MPV might be a useful predictor in diagnosis, a value of 10.35 was indented as the cutoff, probably resulting in sepsis with a sensitivity of $97.8 \%$ and specificity of $78.7 \%{ }^{9}$ Ates et al. determined higher MPV values in septic patients than in the control group and MPV was found to have a cut-off 8.85, sensitivity of $69.6 \%$, and specificity of $62.5 \%{ }^{10}$

There has been no data about association of mean platelet volume with incidence of bloodstream infection in our area as well as in Indonesia. This study aimed to see the association between mean platelet volume and bloodstream infection. The objective of this study is to investigate whether mean platelet volume as a risk factor for bloodstream infection.

\section{MATERIAL AND METHODS}

\section{Study design}

This was a hospital-based cohort prospective study. This research was conducted in the Pediatric Ward Sanglah Hospital Denpasar. Sanglah Hospital is a tertiary-level hospital in Bali. Data were collected between January, $1^{\text {st }} 2016$ until December, $31^{\text {st }} 2018$.

\section{Population and Participants}

The population are patients age $0-18$ years old who admitted to pediatric ward Sanglah, being hospitalized Between January, $1^{\text {st }} 2016$ until December, $31^{\text {st }} 2018$, and is being drawn for blood culture. Inclusion criteria are patient was admitted to pediatric ward, age between $0-18$ years old, no history of antibiotic before admission. Exclusion criteria are hematology and oncology disease, congenital heart defect, history with immunologic disorders such as autoimmune disorders, and those who given longterm corticosteroid therapy. Patient with positive blood culture will be the case and negative blood culture as the control in this study. Sampling was done by consecutive random sampling until the number of samples was fulfilled.

\section{Statistical Analysis}

Statistical analysis using SPSS version 20.0 for Windows. Descriptive analysis will be used to describe the characteristics of the research subjects. Association analysis will be used to assess the association between mean platelet volume and BSI. Odd ratio (OR) calculation will be used to determine risk factor association. All value considered significant if $\mathrm{p}<0.05$.

\section{RESULTS}

Between January, $1^{\text {st }} 2016$ and Dec, $31^{\text {st }} 2018$ there were 89 patients with positive blood cultures and 86 negative blood cultures. In the case group there were 48 (53.9\%) male and 48 (49\%) female, while in the control group there were $63(73.3 \%)$ male and 23 (26.7\%) female. The median age for case group was 14 months, while the median age for control group was 23 months. The majority diagnosis was pneumonia $48.3 \%$ in case group then early onset neonatal sepsis (28.1\%) and meningitis (7.9\%). The characteristics of subject shown in Table 1.

The median of MPV in the case group was 6.67 (4.56-17.08). From the ROC curve, the optimal cut-off value for MPV was determined as 5.59 which exhibited a sensitivity value of 0.80 and a

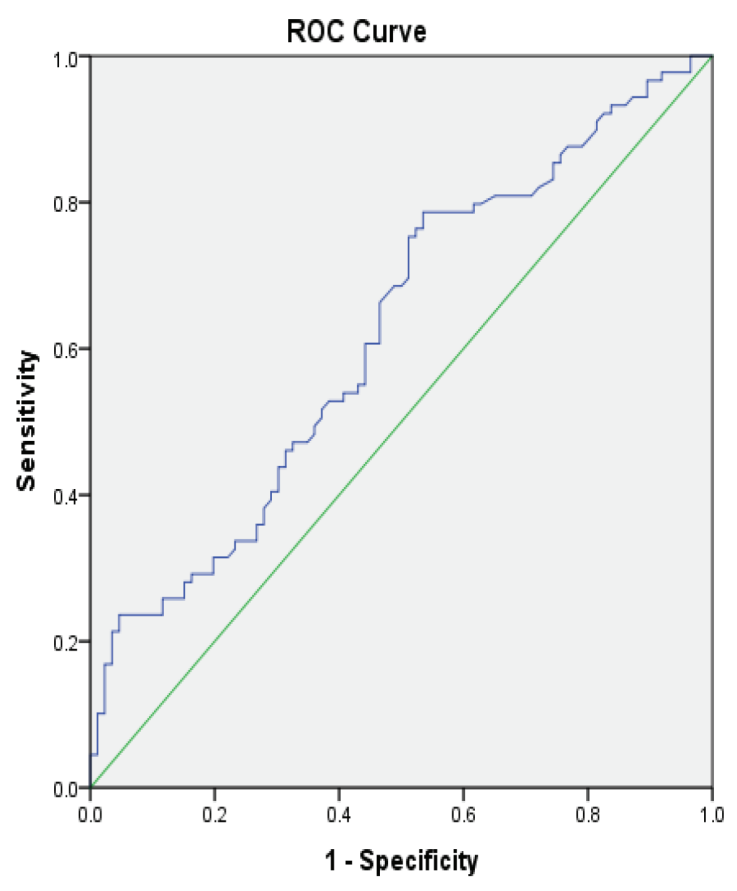

Diagonal segments are produced by ties. 
Table 1 Baseline characteristic $(n=175)$

\begin{tabular}{lcc}
\hline & \multicolumn{2}{c}{ Group } \\
\cline { 2 - 3 } Variable & Case (n=89) & Control (n=86) \\
\hline Age, median (min-max), month & $14(1-215)$ & $23(1-187)$ \\
Gender, n (\%) & & $63(73.3)$ \\
$-\quad$ Male & $48(53.9)$ & $23(26.7)$ \\
$-\quad$ Female & $41(46.1)$ & $307.65(17.84-1109)$ \\
Platelet, median (min-max) & $159.3(6.9-711)$ & $6.12(4.02-13.9)$ \\
MPV, median (min-max) & $6.67(4.56-17.08)$ & $64(74.4)$ \\
Diagnosis, n (\%) & & $7(8.1)$ \\
Pneumonia & $43(48.3)$ & $8(9.3)$ \\
Early Onset Neonatal Sepsis & $25(28.1)$ & $2(2.3)$ \\
Meningitis & $7(7.9)$ & $1(1.2)$ \\
Cholangitis & $2(2.2)$ & $4(4.7)$ \\
Late-Onset Neonatal Sepsis & $1(1.1)$ & \\
Diarrhea with Severe Dehydration & $8(8.9)$ & \\
\hline
\end{tabular}

Table 2 Mean Platelet Count (MPV) as a risk factor for bloodstream infection

\begin{tabular}{cccccc}
\hline & \multicolumn{2}{c}{ Group } & & & \\
\cline { 2 - 3 } Variable & $\begin{array}{c}\text { Case } \\
\mathbf{n}(\%)\end{array}$ & $\begin{array}{c}\text { Control } \\
\mathbf{n}(\%)\end{array}$ & $\begin{array}{c}\text { Odds Ratio } \\
\text { (OR) }\end{array}$ & $\mathbf{9 5 \%} \mathbf{C l}$ & p-value \\
\hline MPV & & & & & \\
$\geq 5.59$ & $72(80.9)$ & $56(65.1)$ & 2.26 & $1.13-4.52$ & 0.019 \\
$<5.59$ & $17(19.1)$ & $30(34.9)$ & & & \\
Total n & $89(100)$ & $86(100)$ & & & \\
\hline
\end{tabular}

Table 3 Multivariate analysis

\begin{tabular}{lccc}
\hline Variable & Adjusted OR & $\mathbf{9 5 \%} \mathbf{C l}$ & p value \\
\hline $\mathrm{MPV} \geq 5.59$ & 2.24 & $1.10-4.57$ & 0.025 \\
\hline
\end{tabular}

specificity value of 0.35 . The AUC was $0.62(95 \% \mathrm{CI}$ 0.54-0.70) for predicting bacterial infection in all 175 enrolled subjects. The ROC curve is presented in Figure 1. The Odd ratio determining the relationship between MPV to BSI was 2.26 with $95 \%$ CI 1.13-4.52 (Table 2). Meanwhile in multivariate analysis found high MPV level was significantly associated with bloodstream infection (OR: 2.24; 95\% CI 1.10-4.57; $\mathrm{p}=0.025$ ) (Table 3).

\section{DISCUSSION}

Early diagnosis and initiation of broad-spectrum antibiotics improve outcome in BSI. Consequently, it is a standard of care to draw blood for cultures before initiation of antibiotic therapy. At present, there is no ideal biomarker for sepsis or bacteremia, and the gold standard isolation and identification of bacteria in the bloodstream may be delayed or absent. ${ }^{4,5}$

In our study from the basic data of research, between January $1^{\text {st }} 2016$ and December $31^{\text {st }} 2018$ there were 175 subjects, where 89 positive blood cultures (bacteremia) as case and 86 negative blood culture as control. From the case group, there were 48 (53.9\%) male and 41 (46.1\%) female, while in the control group there were $63(73.3 \%)$ male and $23(26.7 \%)$ female. There was statistically significant in the gender. The median age for case group was 14 months while the median age for control group was 23 months. This is in accordance with research conducted by Randolph et al., by 2 years of age, adaptive and immune responses have largely approached those of healthy adult levels. The cumulative result of these deficits in immune function is that infants have markedly increased susceptibility to severe infection from various organisms, particularly viruses and encapsulated bacteria. ${ }^{12}$

The majority diagnosis in case group was pneumonia $(46.1 \%)$ then early onset neonatal sepsis (28.1\%) and meningitis (7.9\%). Watson et al. also found the majority of infections causing severe sepsis were either respiratory (37.2\%) or primary bacteremia (25.0\%). Primary bacteremia was particularly common in neonates $(41.8 \%)$ and less common in older children (18.9\%), whereas respiratory infections predominated in older children $(45.9 \%)$ and were less common in neonates (16.9\%). The most common infecting organism was Staphylococcus (17.5\% overall), especially among neonates (25.7\% of all neonatal infections). ${ }^{3}$

MPV is a reflection of both proinflammatory and prothrombotic conditions, where thrombopoietin and numerous inflammatory cytokines, such as interleukin-1 (IL-1), interleukin-3 (IL-3), and interleukin-6 (IL-6) and tumor necrosis factor- $\alpha$ (TNF- $\alpha$ ), regulate thrombopoiesis. Larger platelets, indicating an increased MPV, are functionally, metabolically, and enzymatically more active than smaller ones. Because larger platelets have more intracellular thromboxane A2 and increased levels of procoagulant surface proteins, such as P-selectin and glycoprotein IIIa, they present a greater prothrombotic potential. Moreover, inflammation by itself can induce procoagulant changes and facilitate embolization, which is one of the major causes of death in patients with systemic bacterial infection. Taken together, MPV can be speculated as an integrative measure of the detrimental processes of inflammation and hypercoagulable state in critical illness. $^{8}$

In our study the medians of MPV in the case group were 6.67 (4.56-17.08). The optimal cut-off value for MPV was determined as 5.59, which 
exhibited a sensitivity value of 0.80 and a specificity value of 0.35 . The AUC was 0.62 for predicting bacterial infection in all 175 enrolled subjects. From the references, we found multiple cut-off points on MPV to predict bacteremia (sepsis), Catal et al. grouped the preterm infants in their study as control $(n=100)$ and sepsis $(n=91)$. They showed a significant increase in the MPV in the case of the sepsis group and reported that MPV might be a useful predictor in diagnosis, a value of 10.35 was indented as the cutoff, probably resulting in sepsis with a sensitivity of $97.8 \%$ and specificity of $78.7 \%$ (AUC 0.949; p < 0.001). ${ }^{9}$ In adults, Ates et al. determined higher MPV values in sepsis patients than in the control group and MPV was found to have a cut off 8.123 , sensitivity of $69.6 \%$, and specificity of $62.5 \%{ }^{10}$ Tekin et al. in a cohort study of 43 pediatric patients with acute pyelonephritis investigated higher MPV and the cut off value was 8.2 (AUC 0.906 ), with a sensitivity of $81.4 \%$ and specificity of $86.3 \%$. Dursun et al. study found that MPV had a superior discriminative value to that of CRP (AUC 0.629 and 0.606 respectively) and MPV performed a better performance than CRP in differentiating true bacterial sepsis ( $47.6 \%$ and $42.1 \%$, respectively). ${ }^{11}$

Cho et al. reported that MPV increased with increasing procalcitonin $>1.0 \mathrm{ng} / \mathrm{mL}$. It also shows that an increase in MPV indicates proinflammatory and thrombotic conditions involving several inflammatory mediators, cytokines and endothelial dysfunction. ${ }^{13}$ Eberhardt A et al. reported a study involving 183 sepsis patients that MPV had a significant positive correlation with the occurrence of bacteremia and death so that MPV could be used as a biomarker to assess the severity of sepsis, the higher the MPV the worse the prognosis. ${ }^{14}$ Kukukardali $\mathrm{Y}$ et al. Also found a significant positive correlation between MPV and APACHE score in assessing the severity of sepsis $(r=0.34)$, but no significant correlation was found between MPV and mortality in ICU treated septic patients. ${ }^{15,16}$

In our study, the ODD ratio determined the relationship between MPV to BSI was 2.26 (95\% CI 1.13-4.52) with adjusted OR 2.24 (95\% CI 1.104.57). Ratio more than 1 (2.24) suggests the case will develop to BSI 2.2 times higher than control group, and this ratio could be used as early sign of BSI and early antibiotic administration to prevent the worse outcome. Limitation of this study did not mention the types of bacteria that cause of bloodstream infection.

\section{CONCLUSION}

The MPV $\geq 5,59$ is the risk factor for developed BSI, that we could use this cut-off point to initially administered antibiotic to prevent the worse prognosis (sepsis, multiple organ failure, and death). Longer duration and larger subjects of study, may be able to leverage the magnitude of the problem.

\section{CONFLICT OF INTEREST}

The author declares there is no conflict of interest regarding publication of current article.

\section{FUNDING}

Current study doesn't receive any specific grant from government or any private sector.

\section{ETHICAL CLEARANCE}

Approval of the ethical feasibility of the study was given by the research ethics commission of the medical school of Udayana University/RSUP Sanglah Denpasar with a permit number of 993/ UN14.2.2.VII.14/LP/2019.

\section{REFERENCES}

1. Latief A, Chairulfatah A, Alam A, Pudjiadi AH, Malisie RF, Hadinegoro SRS. National Guide of Indonesian Pediatrician: Guideline for Sepsis in Children. Jakarta: Badan Penerbit Ikatan Dokter Anak Indonesia; 2016.

2. Shime N, Kawasaki T, Saito O, et al. Incidence and risk factors for mortality in pediatric severe sepsis: results from the national pediatric intensive care registry in Japan. Intensive Care Med. 2012;38:1191-7.

3. Watson RS, Carcillo JA, Zwirble WT, Clermont G, Lidicker J, Angus DC. The epidemiology of severe sepsis in children in the United States. Am J Respir Crit Care Med. 2013;167:695-701.

4. Prihardi MT, Hanafie A, Harto S. Hubungan nilai mean platelet volume (MPV) dengan skor APACHE II sebagai prediktor mortalitas pada pasien sepsis berat di Rumah Sakit Umum Pusat Haji Adam Malik Medan. JAP. 2016;4(3):177-82.

5. Becchi C, Malyan MA, Fabbri, LP, Marsili M, Boddi V, Boncinelli S. Mean platelet volume in sepsis: is it a useful parameter?. Minerva Anastesiol. 2006;72:749-56.

6. Bard JD, Tekippe EM. Diagnosis of bloodstream infections in children. J Clin Microbiol. 2016;54(6):1418-24.

7. Chalupa P, Beran O, Herwald H, Kaspř́íková N, Holub M. Evaluation of potential biomarkers for the discrimination of bacterial and viral infections. Infection 2011;39:411-7.

8. Kim CH, Kim SJ, Lee MJ, Kwon YE, Kim YL, Park KS, et al. An increase in mean platelet volume from baseline is associated with mortality in patients with severe sepsis or septic shock. Plos One. 2015;10(3):1-13.

9. Catal F, Tayman C, Tonbul A, et al. Mean Platelet Volume (MPV) may simply predict the severity of sepsis in preterm infants. Clin Lab. 2014;60(7):1193-200.

10. Ates S, Oksuz H, Dogu B, Bozkus F, Ucmak H, Yanit F. Can mean platelet volume and mean platelet volume/platelet count ratio be used as a diagnostic marker for sepsis and systemic inflammatory response syndrome?. Saudi Med J 2015;36(10):1186-90.

11. Dursun A, Ozsoylu S, Akyildiz BN. Neutrophil to lymphocyte ratio and mean platelet volume can be useful markers to predict sepsis in children. Pak J Med Sci. 2018;34(4):918-22. 
12. Randolph AG, McCulloh R. Pediatric sepsis. Virulence. 2014;5:179-89.

13. Cho SY, Yang JJ, Nam YS, Suh JT, Park TS, Lee HJ. Mean platelet volume in patients with increased procalcitonin level. Platelets. 2013;24(3):246-7.

14. Eberhardt A, Lessig F, Schreiter K, Kellner N, Fuchs M, Sablotzki A. Mean platelet volume (MPV) is an outcome marker in sepsis patients. Intern J Infect Dis. 2013;41:12.

15. Kukukardali Y, Onem Y, Terekeci H, Tangi F, Sahan B, Akyol A, et al. Mean Platelet Volume (MPV) in Intensive Care Unit (ICU) Patients: Is it a useful parameter in assessing prediction for mortality?. J Med MedSci. 2010;1(3):61- 64.
16. Aktas G, Kocak M, Taslamacioglu Duman T, Erkus E, Atak B, Sit M, Savli H. Mean Platelet Volume (MPV) as an inflammatory marker in type 2 diabetes mellitus and obesity. Bali Medical Journal. 2018;7(3):650-653. DOI: 10.15562/bmj.v7i3.806.

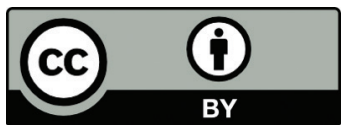

This work is licensed under a Creative Commons Attribution 